\title{
Familial Adenomatous Polyposis: Gardner Syndrome. Case Report
}

Vargas LD², Carrillo Rivera JA2*, Olvera Durán JA3 , Aguirre SB4, Flores

Flores $\mathrm{LR}^{4}$, González Masso JG', Inzunza $\mathrm{EH}^{4}$, Caltenco Solís $\mathrm{RB}^{5}$, González López AI ${ }^{5}$, Alcántar VA ${ }^{6}$ and Narvaez Chavez AR ${ }^{7}$

1Oral and maxillofacial surgeon, Hospital Regional Licenciado Adolfo López Mateos

Instituto de Seguridad Social al Servicio de los Trabajadores del Estado, México

${ }^{2}$ Oral and Maxillofacial Surgeon, Hospital General Dr. Darío Fernández Fierro, ISSSTE, México

${ }^{3}$ Pediatric Surgeon, Hospital Regional Licenciado Adolfo López Mateos ISSSTE, México

${ }^{4}$ Oral and Maxillofacial Surgeon, Private Practice, México

${ }^{5}$ General Surgeon Resident, Hospital General Darío Fernández Fierro, ISSSTE, México

${ }^{6}$ Dental Surgeon, specialist in oral prosthesis and implantology, México

${ }^{7}$ Dental Surgeon specialist in Periodontics, Mexico

*Corresponding author: Jorge Arnulfo Carrillo Rivera, Dental and Maxillofacial Rehabilitation, ISSSTE, México, Tel: 53618677; Email: dr_jorge_carrillo_cmf@hotmail.com

\section{Abstract}

Familiar adenomatous polyposis (FAP) associated to soft tissue or osseous tumors constitute the Gardner's syndrome; from autosomal dominant inheritance as result of adenomatous polyposis coli (APC), gene mutation on chromosome 5q21-22. The risk of colorectal cancer rate $100 \%$ in these patients. Although the FAP has been diagnosed from the year of age, few patients present polyps in the first years of life, being 16 years of age the development of the disease. A case with Gardner's syndrome is presented. The diagnosis was established due to the oral and maxillofacial manifestations, a colectomy was performed at early age.

Key words: Familial Adenomatous Polyposis (FAP); Gardner'S Syndrome; Colectomy

Abbreviations: FAP: Familiar Adenomatous Polyposis; APC: Adenomatous Polyposis Coli.

\section{Resume}

There are two hereditary types of polyposis: adenomatous, which includes familial adenomatous polyposis (FAP), and hamartomatous polyposis. Gardner syndrome is a variant of familial adenomatous polyposis. It is an autosomal dominant condition resulting from mutations of adenomatous polyposis coli (APC) which is a gene on chromosome $5 q 21-22$, which was described by
Devic A Bussy, as a simultaneous presentation of colorectal polyposis associated with other findings [1].

In Gardner syndrome, the three embryological layers are affected. FAP is characterized by adenomatous polyps in the colon and rectum, which have a tendency to become malignant, starting with intestinal obstruction or bleeding from the lower digestive tract. Mesodermal lesions include osteomas in skull and facial bones, retained or supernumerary teeth and odontomas [2,3]. Bone tumors appear at puberty and precede the onset of polyposis. It is more usual to find them in the jaw and 


\section{Medical Journal of Clinical Trials \& Case Studies}

frontal bone. The most common ectodermal anomalies are: epidermoid cysts, desmoid tumors, leiomyomas, or pigmented skin $[2,3]$. The pigments in the ocular fundus are part of a congenital hypertrophy of the retina epithelium [2,3].

Although FAP has been diagnosed since one year of age, few patients have polyps in the first years of life, being 16 years the average age of development of them, 29 years the onset of intestinal symptoms and 40 years the appearance of colorectal cancer, if the appropriate treatment is not carried out. The youngest patient with colon cancer was diagnosed at 8 years of age [2,3]. According to Camuzard, the worldwide prevalence of FAP is $1 / 24,000$ inhabitants [4]. The diagnosis of Gardner syndrome is complicated due to the multiple variations of the clinical findings that exist $[5,6]$. We report a case in which the diagnosis was established due to oral and maxillofacial manifestations in the patient, who underwent colectomy at an early age [7-9].

\section{Case Report}

A 12-year-old female patient who presents with an increase in volume at the mandibular angle on the right side, with pain at the digit pressure, which appears after a trauma in the area. Radio graphically, a radiopaque lesion of $2 \times 2$ centimeter is observed in diameter with odontoma characteristics between the roots of the lower central incisors and a tooth included in the mental region; A radiopaque lesion was also observed in the right mandibular angle (Figures 1A \& 1B).

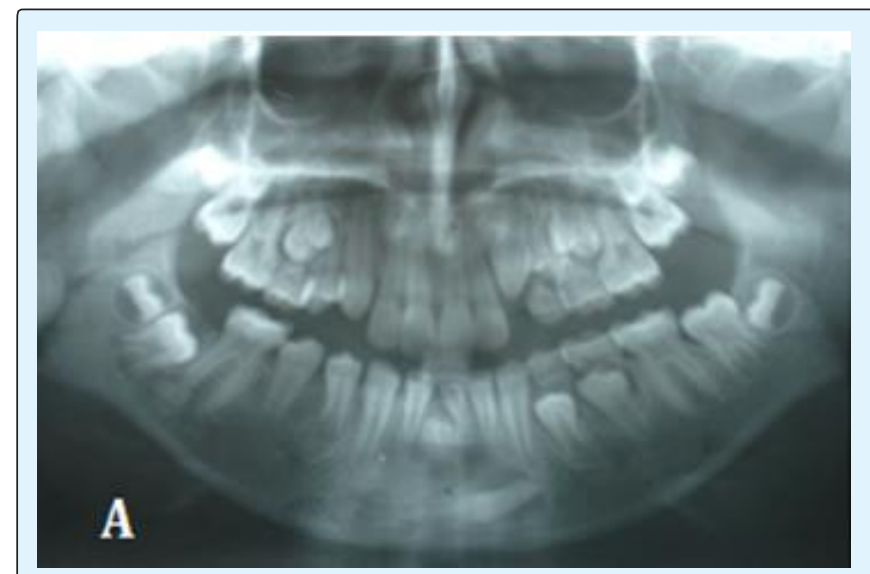

Figure 1A: Orthopantomography, lesions are observed between the roots of the lower central incisors and in the mental region. 


\section{Medical Journal of Clinical Trials \& Case Studies}

The histopathological diagnosis of the excisional biopsy was odontoma and osteoma, both characteristic lesions of Gardner's syndrome, which is why the study protocol begins, which consists in indicating endoscopy and colonoscopy. During endoscopy several polypoid lesions are removed, diagnosing gastric polyps of fundus and body Yamada I; in the colonoscopy, multiple polypoid lesions are observed in the mucosa of the caecum, ascending colon, transverse and descending, sigmoid and rectum. Biopsies of lesions are performed. In the histopathological diagnosis mucosa of the caecum, colon, splenic angle, hepatic angle: tubular adenoma without atypia is reported. For this reason, the assessment is requested by the pediatric surgery service, who kept it under observation for 5 months, until it came to the emergency room presenting with fresh blood evacuations on three occasions, which is why it is scheduled to perform total colectomy and anastomosis. Rectal (ileoproctoanastomosis) (Figures 3A-3D).

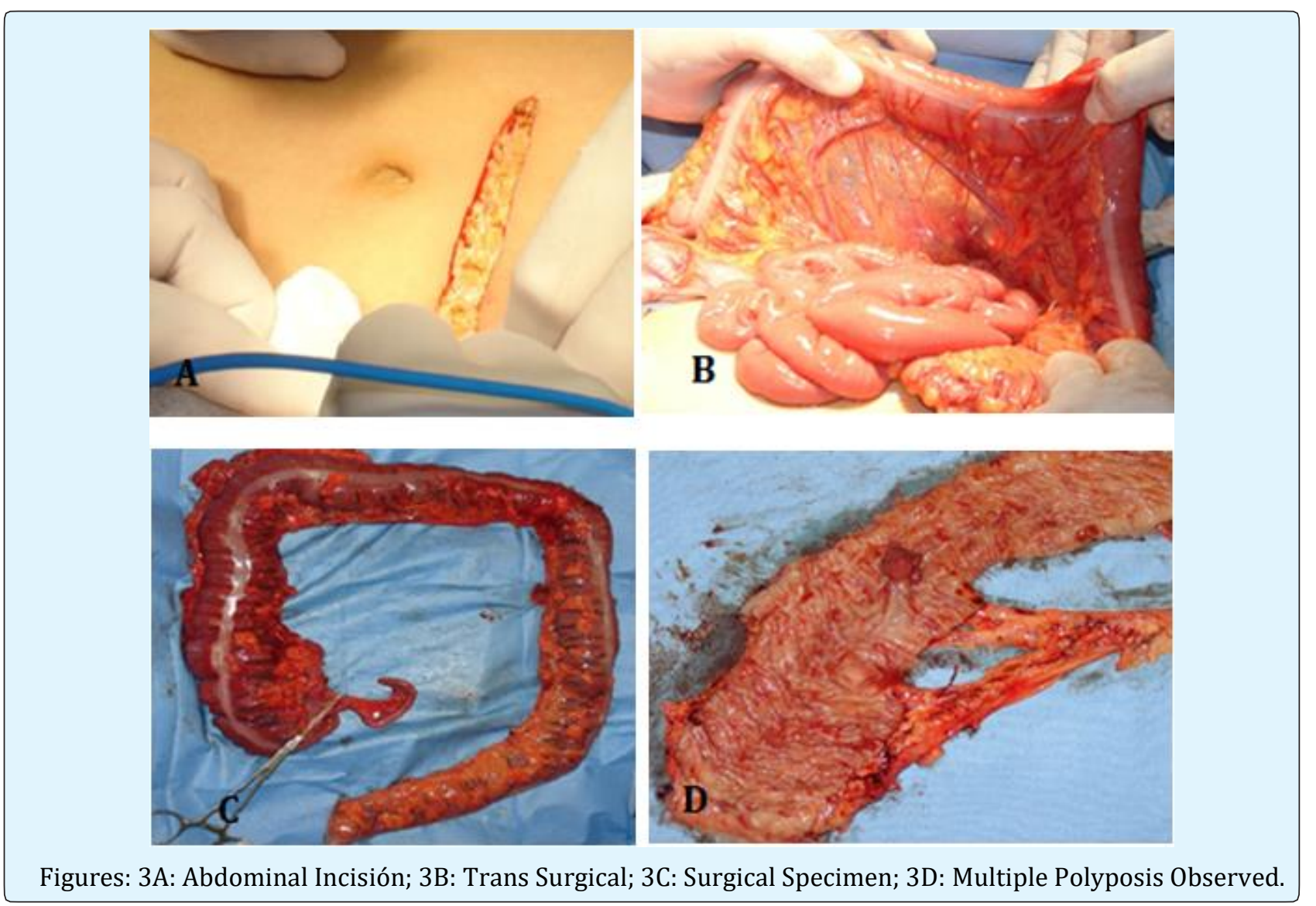

\section{Discussion}

Gardner syndrome is an autosomal dominant condition of the colon characterized by the presence of innumerable polyps. The incidence of this disorder is between 1 in 8,300 and 1 in 14,025 live births, affecting both genders equally, with a uniform global distribution $[6,7]$. Extracolonic manifestations are associated with colon polyps, such as bone tumors, desmoid tumors, epidermoid cysts, pilomatrixomas, sebaceous cysts, leiomyomas, dental anomalies, congenital hypertrophy of the retinal pigment epithelium, gastroduodenal and intestinal polyps [7,9]. thin, and a special predisposition for periambular and thyroid cancer. Each intestinal polyp will eventually become malignant if colectomy is not performed. The patient's control should be periodic, until the appearance of polyps, if these appear before puberty, colectomy may be delayed until then, but if there is 


\section{Medical Journal of Clinical Trials \& Case Studies}

symptoms (rectal bleeding, low digestive tract hemorrhage) or in the biopsy dysplasia is seen, the colectomy will be carried out immediately, at any age $[10,11]$. In our patient, at 12 years, Gardner's syndrome is confirmed with polyposis observed in colon, deciding colectomy, since currently, prophylactic exeresis of the colon is the only effective treatment to prevent the malignant degeneration of one or more colonic polyps [12-14].

\section{References}

1. Devic A, Bussy MM (1912) Un cas de polypose adénomateuse généralisée àtout l'intestin. Arch Mal App Dig 6: 278.

2. Gardner EJ (1951) A genetic and clinical study of intestinal polyposis, A predisposing factor for carcinoma of the colon and rectum. Am J Hum Genet 3(2): 167-176.

3. Bulow S (1987) Familial polyposis coli. Dan Med Bull 34: 1.

4. Camuzard JF, Vaille G, Santini J (1990) Le syndrome de Gardner. Revue de la littérature. A propos d'une forme familiale. Otolaryngol Chir Cervicofac 107: 509.

5. Bisgaard ML, Fenger K, Bulow S, Niebuhr E, Mohr J (1994) Familial adenomatous polyposis (FAP): Frequency, penetrance, and mutation rate. Hum Mutat 3(2): 121-125.
6. Bronner MP (2003) Gastrointestinal polyposis syndromes. Am J Med Genet A 122(4): 335-341.

7. Oku T, Takayama T, Sato Y, Takada K, Hayashi T, et al. (2004) A case of Gardner syndrome with a mutation at codon 1556 of APC: A suggested case of genotypephenotype correlation in dental abnormality. Eur J Gastroenterol Hepatol 16(1): 101-105.

8. Nandakumar G, Morgan JA, Silverberg D, Steinhagen RM (2004) Familial polyposis coli: Clinical manifestations, evaluation, management and treatment. Mt Sinai J Med 71(6): 384-391.

9. Koen S, Hernández NA, Akiko Ono (2003) Familial adenomatous polyposis. Presentation of a clinical case. Rev Med Uruguay 19(2): 178-181.

10. Nuñez Nuñez R, Gómez GE, Moreno HC, Romero AA, Santamaría SJI (2006) Poliposis adenomatosa familiar: síndrome de Gardner. Cir Pediátrica 19: 111114.

11. Gorlin RJ, Cohen MM, Hennekam RCM (2001) Syndromes of the head and neck. $4^{\text {th }}$ (Edn.), Oxford University Press, New York, pp: 437-441.

12. Buch B, Noffke C, de Kock S (2001) Gardner's syndrome: the importance of early diagnosis: a case report and a review. SADJ 56(5): 242-245.

13. Larsen PR, Kronenberg HM, Melmed S, Polonsky KS (2003) Williams textbook of endocrinology. Philadelphia: Saunders, pp: 177-279. 